\title{
Adrenal Incidentaloma and Adrenocortical Carcinoma: A Clinical Guideline on Treating the Unexpected and a Plea for Specialized Care
}

\author{
S.H.A. Brouns, T.M.A. Kerkhofs, I.G.C. Hermsen and H.R. Haak \\ Máxima Medical Center, Eindhoven \\ The Netherlands
}

\section{Introduction}

An adrenal incidentaloma is an important clinical finding that is often considered harmless, but can be the tip of the iceberg. The term incidentaloma indicates an adrenal mass larger than $1 \mathrm{~cm}$, incidentally discovered during imaging studies performed for reasons other than suspicion of adrenal pathology. Lesions identified during staging procedure or work-up for patients with a known extra-adrenal malignancy are not considered to be an incidentaloma (Young, Jr. 2000; Grumbach et al. 2003; Young, Jr. 2007; Singh \& Buch 2008; Terzolo et al. 2009; Androulakis et al. 2011).

The entity incidentaloma is not a new finding and has been reported for many years (Grumbach et al. 2003; Young, Jr. 2007; Singh \& Buch 2008; Terzolo et al. 2009; Androulakis et al. 2011). Because of the increased use of imaging techniques and improvement in abdominal imaging, the frequency of incidentaloma findings is increasing as well. Recent studies using high-resolution computed tomography (CT) have reported an estimated prevalence of $4 \%$ (Young, Jr. 2007; Singh \& Buch 2008). In autopsy studies the prevalence ranged $0.2 \%-8.7 \%$, depending on definitions used and age group, as there is an agedependent occurrence of adrenal incidentalomas (Young, Jr. 2000; Grumbach et al. 2003; Young, Jr. 2007; Singh \& Buch 2008; Terzolo et al. 2009; Androulakis et al. 2011). The estimated prevalence in patients younger than 30 years is $<1 \%$, in contrast to a $7 \%$ frequency in patients 70 years of age or older (Young, Jr. 2007). With an aging population and advanced radiological techniques becoming more widely available, the increasing frequency of adrenal incidentalomas is of growing importance.

When an incidentaloma is found, it is of vital importance to make an early and reliable differentiation between benign and (potentially) malignant lesions, but also to assess tumor functionality. The mass can originate from either the adrenal medulla or cortex (Androulakis et al. 2011). Consequently, a spectrum of different pathological conditions may underlie an incidentaloma, all requiring a different therapeutic approach. As much as 38 different diagnoses have been reported in patients with a serendipitous discovered adrenal tumor (Young, Jr. 2000). Most adrenal incidentalomas are clinically nonhypersecretory benign adenomas, with an estimated frequency of $70-80 \%$, which cause no health problems. However, in $5-20 \%$ of patients who have no endocrinological signs or symptoms, analysis reveals subclinical hypercortisolism (Grumbach et al. 2003; Young, Jr. 2007; Singh \& Buch 
2008; Terzolo et al. 2009). Other frequently reported diagnoses besides a nonfunctioning adenoma include adrenocortical carcinoma (ACC), pheochromocytoma, metastasis and aldosterone-producing adenoma. Although malignancy is rare, it is of great clinical concern because of the poor prognosis (Grumbach et al. 2003; Terzolo et al. 2009).

After recognition of an incidentaloma both patient and physician are faced with uncertainties regarding the course, likelihood of a malignancy and treatment of the adrenal mass. Unfortunately, no diagnostic or therapeutic strategy has been validated in prospective clinical trials. Thus, the diagnostic work-up as well as management of an incidentaloma is a growing public health challenge (Young, Jr. 2007; Singh \& Buch 2008; Terzolo et al. 2009).

The goal of this chapter is to provide a diagnostic guideline, which contains information about clinical presentation, biochemical work-up and radiological imaging. In addition, this chapter offers practical recommendations for the management of adrenal incidentaloma, including surgery and follow-up. Also, therapeutic options for adrenal carcinoma are discussed. Furthermore, we present organisational recommendations concerning the management of adrenal incidentaloma and emphasize the need for centralization of adrenal disease-research and patient care. This will provide patients with an opportunity to receive optimal care, as the beneficial effects of specialization have been proven multiple times in other rare diseases.

\section{Diagnostics of incidentaloma}

The first step in the evaluation of adrenal incidentalomas is establishing the definition of the tumor type, beginning with a thorough history taking and extensive physical examination, with attention to signs or symptoms of hormonal overproduction, a malignancy or pheochromocytoma. Furthermore, hormonal work-up and radiological imaging is required in the diagnostic evaluation of the adrenal mass.

\subsection{History and physical examination}

\subsubsection{History}

Signs suggestive of hormonal overproduction may include Cushing's characteristics, symptoms of hyperaldosteronism or sex hormone excess. Cushing's syndrome may be asymptomatic in the event of subclinical disease or present with weight gain and central obesity, flushes, proximal muscle weakness, and polydipsia. Furthermore, cognitive changes, such as irritability, depression or restlessness, may also be present. Hirsutism, acne, gynaecomastia and oligomenorrhoe may be symptoms of hypercortisolism or sex hormone overproduction. Features of primary hyperaldosteronism are nocturia, muscle cramps and polyuria in case of hypokalaemia and palpitations (Young, Jr. 2007; Singh \& Buch 2008; Androulakis et al. 2011).

The classic triad of symptoms associated with a pheochromocytoma includes episodic headaches of variable duration, tachycardia and generalized sweating. However, this combination of symptoms is present in only a small percentage of patients $(10 \%)$ (Nieman 2010). Characteristics less commonly present are pallor, dyspnea and anxiety and secondary, complaints of hyperglycemia, unintentional weight loss, arrhythmias and cardiomyopathy (Young, Jr. 2007; Androulakis et al. 2011).

An adrenocortical carcinoma may either present with signs of adrenal hypersecretion as mentioned above or symptoms related to mass effect, such as abdominal fullness or abdominal pain. Cancer-related signs (e.g. fever, unintentional weight loss) are less 
frequently present (Young, Jr. 2007; Singh \& Buch 2008; Terzolo et al. 2009; Androulakis et al. 2011).

\subsubsection{Physical examination}

Clinical features of Cushing's syndrome detected during physical examination are hypertension, central obesity, striae, facial rounding ('moon face'), supraclavicular and dorsocervical fat pads ('buffalo hump'), proximal muscle weakness, clitoris hypertrophy, acne and hirsutism. Primary aldosteronism is characterized by hypertension. In rare cases, female patients can present with signs of virilization (e.g. acne, hirsutism) as a result of testosterone excess. In contrast, an estrogen secreting adrenal lesion can produce signs of feminization, such as gynaecomasty in the male patient. A pheochromocytoma may present with hypertension (paroxysmal or sustained), orthostatic hypotension, pallor and sweating on physical examination. Adrenocortical carcinoma may as well present signs of hormonal overproduction mentioned above. In addition, a palpable mass may be present at abdominal examination (Young, Jr. 2007; Singh \& Buch 2008; Terzolo et al. 2009; Androulakis et al. 2011).

\begin{tabular}{lc}
\hline Causes & $\begin{array}{c}\text { Estimated } \\
\text { prevalence }\end{array}$ \\
\hline
\end{tabular}

\section{Adenoma}

Subclinical Cushing's Syndrome

Primary aldosteronism Androgen overproduction
Weight gain with central obesity, flushes,

$9 \%$ proximal muscle weakness, polydipsia, cognitive changes

\section{$1.2 \%$ Nocturia, muscle cramps, polyuria, palpitations}

Rare Hirsutism, acne, oligomenorrhoe

Nonfunctioning $\quad 73.9 \% \quad-$

\begin{tabular}{ccl} 
Pheochromocytoma & $4.7 \%$ & $\begin{array}{l}\text { Episodic headaches, tachycardia, generalized } \\
\text { sweating, pallor, dyspnea, anxiety }\end{array}$ \\
$\begin{array}{c}\text { Malignancy } \\
\begin{array}{c}\text { Adrenocortical } \\
\text { carcinoma }\end{array}\end{array}$ & $4.8 \%$ & $\begin{array}{l}\text { Symptoms of functioning mass (see above), } \\
\text { abdominal pain or fullness } \\
\text { Metastasis }\end{array}$ \\
\hline
\end{tabular}

Table 1. Prevalence and clinical presentation of the most frequent types of adrenal incidentaloma (Young, Jr. 2007, Singh and Buch 2008)

\subsection{Hormonal evaluation}

Additional hormonal work-up is necessary in the evaluation of tumor functionality. Although an adrenal mass may appear clinically nonhypersecretory, up to $20 \%$ of patients with an incidentaloma may have hormonal dysfunction, which might be associated with a higher risk of morbidity, such as metabolic disorders and cardiovascular disease (Singh \& Buch 2008; Androulakis et al. 2011). 


\subsubsection{Subclinical Cushing's Syndrome}

The most frequently diagnosed endocrine alteration in patients with an incidentaloma is Subclinical Cushing's Syndrome (SCS), which refers to autonomous and dysregulated cortisol secretion by the tumor, which may cause mild cortisol excess without typical signs and symptoms of hypercortisolism (Young, Jr. 2007; Singh \& Buch 2008; Androulakis et al. 2011). It is also known as subclinical autonomous glucocorticoid hypersecretion (Grumbach et al. 2003). The average prevalence is 9\% (range 1-29\%, depending on criteria used)(Singh and Buch 2008). It is difficult to characterize, since clinical Cushing's syndrome is not present and patients may have normal 24-hour urinary free cortisol secretion (Terzolo et al. 2009). Therefore, late-night salivary cortisol and/or overnight dexamethasone $(1 \mathrm{mg})$ suppression test is recommended to detect subclinical hypercortisolism (Grumbach et al. 2003; Nieman 2010). The optimal cut-off value is much discussed. A cortisol value greater than $138 \mathrm{nmol}$ per liter ( 5 microg/dL) in response to $1 \mathrm{mg}$ dexamethasone overnight is associated with glucocorticoid overproduction and has an estimated sensitivity of $98 \%$ and specificity of $80-98 \%$ (Singh and Buch 2008). When a level between $50-70 \mathrm{nmol} / \mathrm{L}(1.8-2.5 \mathrm{microg} / \mathrm{dL})$ is used as cutoff value, confirmatory testing is indicated, such as midnight plasma cortisol or serum ACTH level (Grumbach et al. 2003; Young, Jr. 2007; Singh \& Buch 2008; Terzolo et al. 2009).

Recent studies and own observations identify urinary steroid profiling as a very promising screening instrument for early differentiation between benign and malignant tumors. A quantitative analysis of steroid precursors by gas chromatography and mass spectrometry reveals steroid patterns associated with particular clinical problems. A recently designed algorithm screens for nine metabolites in a 24-hour urine sample and has impressive test characteristics with high sensitivity and specificity (Taylor A \& Arlt 2010).

\subsubsection{Primary aldosteronism}

Primary aldosteronism (Conn's syndrome) is present in approximately $1.2 \%$ of patients with an adrenal incidentaloma (Androulakis et al. 2011). The textbook presentation comprises hypertension and hypokalaemia, however almost $40 \%$ of patients are normokalaemic (Young, Jr. 2000; Singh \& Buch 2008). Therefore, serum potassium level is not considered a reliable screening method. Hormonal work-up includes routine measurement of ambulatory morning plasma aldosterone concentration to plasma renin activity ratio (PAC/PRA ratio) in hypertensive patients. This can be performed during treatment with antihypertensive drugs with the exception of beta blockers and aldosterone antagonists. A PAC/PRA ratio $\geq 30$ and plasma aldosterone concentration greater than $0.5 \mathrm{nmol} / \mathrm{L}$ is indicative of autonomous aldosterone secretion. Since the PAC/PRA ratio is influenced by time of sampling and posture of the patient, the diagnosis needs to be confirmed by additional measurement of mineralocorticoid secretory autonomy (e.g. saline infusion test) (Young, Jr. 2000; Grumbach et al. 2003; Young, Jr. 2007; Singh \& Buch 2008; Nieman 2010).

\subsubsection{Sex hormone overproduction}

Sex hormone-secreting adrenal tumors rarely present as an incidentaloma, since they are usually symptomatic (e.g. hirsutism, virilization, gynaecomasty). Androgen overproduction 
may be a feature of ACC, but measurement of androgens and their precursors in serum has a low diagnostic accuracy in differentiating malignant from benign adrenal masses. Routine measurement of androgen or estrogen production is not necessary in patients with an incidentaloma (Young, Jr. 2000; Young, Jr. 2007)

Nonclassical congenital adrenal hyperplasia may cause unilateral or bilateral adrenal lesions and is an uncommon cause $(<1 \%)$ of incidentalomas. Routine cosyntropinstimulation testing with measurement of cortisol precursors is not warranted, unless the diagnosis is suspected based on clinical manifestation (hirsutism, acne, menstrual irregularities) or the presence of bilateral adrenal masses (Young, Jr. 2000; Young, Jr. 2007; Nieman 2010).

\subsubsection{Silent pheochromocytoma}

The estimated prevalence of a pheochromocytoma among patients with an adrenal incidentaloma is $4-7 \%$ Although it is mostly a benign condition, it may cause significant morbidity and mortality. Hypertension is constantly present in only half of the patients and paroxysmal in approximately $30 \%$. It is essential to diagnose a catecholamine-secreting pheochromocytoma, since it has the potential to cause cardiac arrhythmias and hemodynamic instability even in asymptomatic patients. Therefore, routine measurement of fractionated metanephrines and catecholamines in 24-hour urine specimen is indicated in all patients presenting with an incidentaloma. Recent research reported the superiority of determination of fractionated plasma free metanaphrines, with a diagnostic sensitivity of $99 \%$ and specificity of $89 \%$. However, this method is not widely available (Grumbach et al. 2003; Young, Jr. 2007; Singh \& Buch 2008; Terzolo et al. 2009; Nieman 2010; Androulakis et al. 2011).

\subsection{Radiologic evaluation}

Imaging studies that brought the incidentaloma to light should be reviewed with a focus on the adrenal glands, but will often be insufficient. The goal is to distinguish adenomas from malignant masses. Several imaging characteristics are used to assess the malignant potential and to provide information concerning appropriate management.

\subsubsection{Computed Tomography}

It is advised to perform an unenhanced CT-scan to help distinguish adenomas from nonadenomas, followed by a delayed contrast-enhanced sequence and computed wash-out percentage (Hamrahian et al. 2005). Attenuation of adrenal masses is measured in Hounsfield Units. A low attenuation on CT before contrast administration indicates high lipid content and is found in adenomas. However, around 30\% (range 10-40\%) of adenomas do not have a large lipid content and consequently may be difficult to discriminate from nonadenomas.

Furthermore, size and appearance of the adrenal lesion may as well help to differentiate between benign and malignant tumors. The probability of an incidentaloma being an ACC is directly related to size of the lesion. A diameter greater than $4 \mathrm{~cm}$ is reported to have $90 \%$ sensitivity for identifying ACC, but a low specificity, since only approximately $25 \%$ of lesions greater than $4 \mathrm{~cm}$ are malignant. In addition, calcifications, necrosis and hemorrhage are indicative of a malignancy (Young, Jr. 2000; Terzolo et al. 2009; Nieman 2010). 


\begin{tabular}{|c|c|c|c|c|}
\hline $\begin{array}{l}\text { CT- } \\
\text { characteristic }\end{array}$ & Adenoma & $\begin{array}{l}\text { Pheochromocy } \\
\text { toma }\end{array}$ & $\begin{array}{l}\text { Adrenocortical } \\
\text { carcinoma }\end{array}$ & Metastasis \\
\hline Size & Usually $<4 \mathrm{~cm}$ & $\begin{array}{l}\text { Large, usually } \\
>3 \mathrm{~cm}\end{array}$ & $\begin{array}{l}\text { Large, usually } \\
>3 \mathrm{~cm}\end{array}$ & $\begin{array}{l}\text { Variable, } \\
\text { usually }<3 \mathrm{~cm}\end{array}$ \\
\hline Shape & $\begin{array}{l}\text { Round, smooth } \\
\text { margins }\end{array}$ & $\begin{array}{l}\text { Round, smooth } \\
\text { margins }\end{array}$ & $\begin{array}{l}\text { Irregular, } \\
\text { unclear } \\
\text { margins }\end{array}$ & $\begin{array}{l}\text { Oval, irregular } \\
\text { margins }\end{array}$ \\
\hline $\begin{array}{l}\text { Attenuation on } \\
\text { unenhanced CT }\end{array}$ & $<10 \mathrm{HU}$ & $>10 \mathrm{HU}$ & $>10 \mathrm{HU}$ & $>10 \mathrm{HU}$ \\
\hline $\begin{array}{l}\text { Washout (in } 10 \\
\text { minutes) }\end{array}$ & Rapid, > 50\% & Delayed, $<50 \%$ & Delayed, < 50\% & Delayed, $<50 \%$ \\
\hline Growth rate & Stable & Slow (usually) & Rapid (usually) & Variable \\
\hline Other features & $\begin{array}{l}\text { Rarely } \\
\text { necrosis, } \\
\text { hemorrhage or } \\
\text { calcification }\end{array}$ & $\begin{array}{l}\text { Hemorrhage, } \\
\text { cystic necrotic } \\
\text { areas }\end{array}$ & $\begin{array}{l}\text { Necrosis, } \\
\text { hemorrhage, } \\
\text { calcification }\end{array}$ & $\begin{array}{l}\text { Hemorrhage, } \\
\text { cystic necrotic } \\
\text { areas }\end{array}$ \\
\hline
\end{tabular}

HU $=$ Hounsfield Units

Table 2. CT characteristics of the most frequent types of an incidentaloma (Young, Jr. 2000; Young, Jr. 2007; Terzolo et al. 2009)

\subsubsection{Magnetic Resonance Imaging}

Magnetic Resonance Imaging (MRI) is equally effective as CT in differentiating benign from malignant adrenal masses (Grumbach et al. 2003). A normal adrenal gland is characterized by an equal or slightly lower intensity than that of the liver on T1 and T2. In contrast, malignant lesions are hyperintense on T2-weighted images (Young, Jr. 2000; Androulakis et al. 2011).

\subsubsection{Positron Emission Tomography}

Additional advanced radiological testing is generally not indicated. 18-Fluoro-2-deoxy-Dglucose positron emission tomography (PET) is highly sensitive in identifying malignant lesions. However, it is of limited use regarding the evaluation of adrenal incidentaloma (in patients without a prior history of malignancy) (Young, Jr. 2007; Singh \& Buch 2008; Boland 2011)

\subsection{Fine-Needle Aspiration}

There is no evidence to support the routine use of computed tomography-guided fineneedle aspiration (FNA) in the diagnostic evaluation of an incidentaloma. It is rarely informative, since it has a high-false negative rate, and there is a risk of complications, such as hemorrhage, abdominal pain, pancreatitis and pneumothorax. Moreover, its added value over radiological imaging has not been established. In case of a suspected pheochromocytoma FNA is contraindicated, since manipulation of the tumor can potentially cause a hypertensive crisis. Furthermore, biopsy of an adrenocortical carcinoma may lead to tumourspill and consequently tumor recurrence along the needle track. The only role of FNA in the evaluation of an incidentaloma is in confirming metastatic disease in patients with a known extra-adrenal malignancy without other signs of metastases (Young, 
Adrenal Incidentaloma and Adrenocortical Carcinoma:

A Clinical Guideline on Treating the Unexpected and a Plea for Specialized Care

Jr. 2000; Grumbach et al. 2003; Young, Jr. 2007; Quayle et al. 2007; Singh \& Buch 2008;

Terzolo et al. 2009; Nieman 2010).

\section{Diagnostic evaluation}

The work-up leads to a preliminary conclusion which determines further management. The spectrum varies from benign adenoma to the presumption of malignancy or a pheochromocytoma.

\subsection{Suspect adenoma}

As noted before, the first step in evaluation of an adrenal incidentaloma is discrimination between a benign or malignant adrenal mass, in which radiological imaging by CT-scan has a fundamental role. Most adrenal incidentalomas exhibit characteristic features of adrenocortical adenoma (ACA). Adenomas typically present as small $(<4 \mathrm{~cm})$ lesions, with clear margins and high lipid content, which is characterized by low attenuation $(<10 \mathrm{HU})$ on unenhanced CT. Furthermore, they display rapid washout of contrast medium (e.g. more than $50 \%$ after 10 minutes) (see figure 1) (Androulakis et al. 2011).

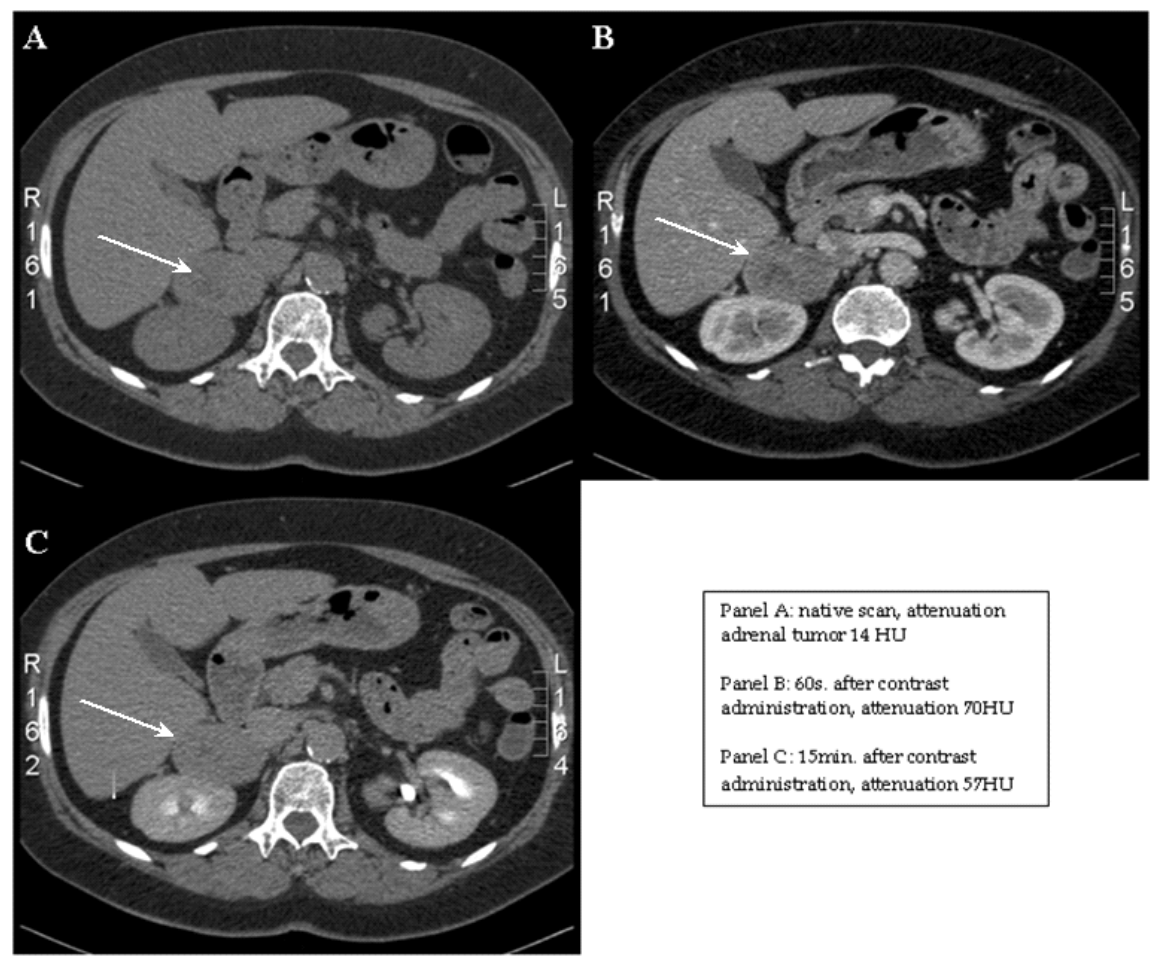

Fig. 1. Washout sequence of an adrenocortical adenoma 
In patients with non-functioning ACA, size of the adrenal mass is the major determinant in choice of management (Nieman 2010; Androulakis et al. 2011). Over 60\% of incidentalomas less than $4 \mathrm{~cm}$ in diameter are ACA, in contrast only $2 \%$ are malignant. For a small non-functioning adenoma surgical resection is not necessary, follow-up through CT-imaging and biochemical screening will suffice. In lesions larger than $6 \mathrm{~cm}$ the prevalence of ACC increases to approximately $25 \%$ and surgery is indicated (Singh \& Buch 2008). Management of adrenal masses with a diameter between 4 to $6 \mathrm{~cm}$ is less well defined. Because of a higher risk of malignancy in this subgroup of patients, surgical approach is recommended in most cases.

In about $20 \%$ of adrenal adenomas hormonal work-up reveals overproduction of aldosterone $(0.5-1 \%)$ or cortisol $(5-20 \%)$, which may have a negative influence on patient's health. Primary hyperaldosteronism is associated with increased risk of cardiovascular events. Additionally, patients with SCS may be at risk for potential morbidity attributable to cortisol overproduction. However, progression to clinical overt Cushing's syndrome is uncommon. Surgical resection is considered the treatment of choice when biochemical overproduction is confirmed.

\subsection{Suspect pheochromocytoma}

It is essential to exclude a pheochromocytoma in patients presenting with an adrenal incidentaloma, because they are potentially lethal even when clinically asymptomatic (Young, Jr. 2007). Increased metanephrines and catecholamines in 24-hour urine specimen or fractionated plasma free metanaphrines in combination with features on $\mathrm{CT}$, such as increased attenuation on unenhanced CT $(>10 \mathrm{HU})$, prominent vascularity of the mass and delayed washout of contrast $(<50 \%$ after 10 minutes), are highly suggestive of a pheochromocytoma (Terzolo et al. 2009). Characteristics indicative of pheochromocytoma on MRI include hyperintensity on T2-weighted imaging, with approximately $92 \%$ sensitivity and $88 \%$ specificity (Androulakis et al. 2011). When a pheochromocytoma is suspected, surgical treatment is indicated. Patients should be adequately prepared pre-operatively by adrenergic blockade, to prevent a perioperative hypertensive crisis caused by manipulation of the tumor and subsequent catecholamine-release.

\subsection{Suspect malignancy}

\subsubsection{Adrenocortical carcinoma}

The risk of a malignancy is the main concern in patients with an incidentaloma. The prevalence of ACC in these patients without a history of malignancy is estimated at $4.8 \%$, which makes it the most commonly identified adrenal malignancy (Terzolo et al. 2009). It is an aggressive malignancy with a median survival of 19 months (range 8-29 months), as calculated from data of 191 patients diagnosed between 2000 and 2010 in The Netherlands. Prognosis of ACC is still mainly dependent on stage at diagnosis (Fassnacht \& Allolio 2009). For that reason it is vital to make accurate decisions regarding the necessary diagnostic and therapeutic measurements.

A smaller tumor size corresponds with a lower tumor stage and consequently better prognosis. The risk of ACC is, as mentioned, associated with mass size. However, because the prevalence of adrenal adenoma is age-dependent, the presence of small adrenal masses in young patients should raise major concern of a potential malignancy. A malignant adrenal lesion typically presents as a larger mass $(>6 \mathrm{~cm})$ and is characterized by an irregular border, 
high attenuation on unenhanced CT (> $10 \mathrm{HU})$ and slow washout after contrast administration (see figure 2) (Terzolo et al. 2009). Own observations from the authors show that although an ACC may appear clinically non-functioning, in about $80-95 \%$ additional hormonal work-up and urinary steroid profiling reveals presence of hormone excess.

When an adrenal malignancy is suspected, further investigation concerning cancer staging is warranted before directing the patient to surgery.

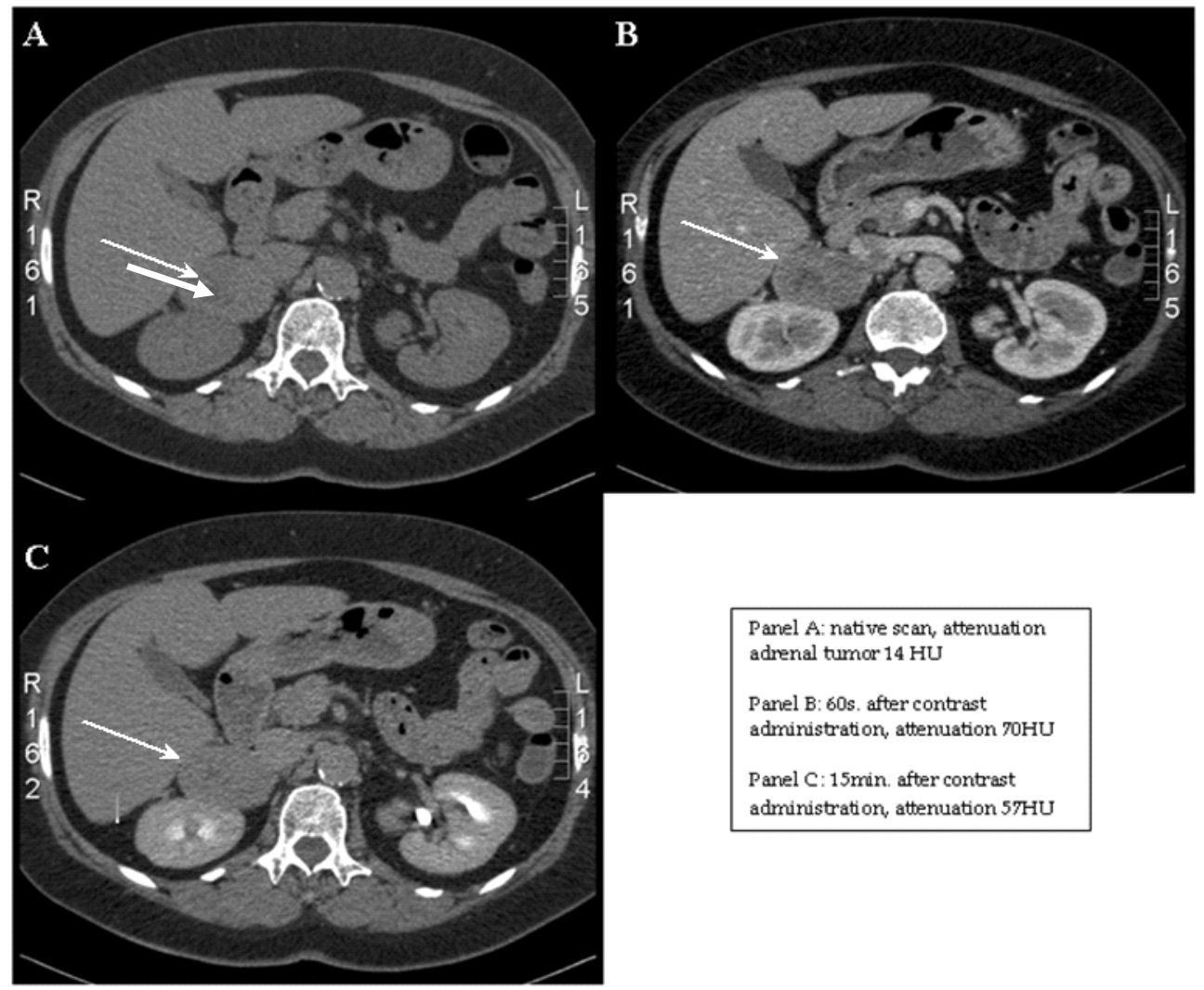

Fig. 2. Washout sequence of an adrenocortical carcinoma

\subsubsection{Metastasis}

Tumors that frequently metastasize to adrenal glands include carcinomas of lungs, esophagus, kidney, colon, breast, liver, pancreas and stomach (Young, Jr. 2007). Metastases frequently occur bilateral and are variable in size, mostly smaller than $3 \mathrm{~cm}$. Abdominal imaging may also reveal the presence of necrosis, hemorrhage or calcifications (Young, Jr. 2000). Adrenal metastasis may cause beginning adrenal insufficiency. The suspicion of metastasis in an incidentaloma has clinical implications for prognosis and management and the search for a primary neoplasm is indicated. Resection of an isolated adrenal metastasis is associated with improved (disease-free and overall) survival. However, only in a limited number of cases adequate treatment of adrenal metastasis is possible (Terzolo et al. 2009). 


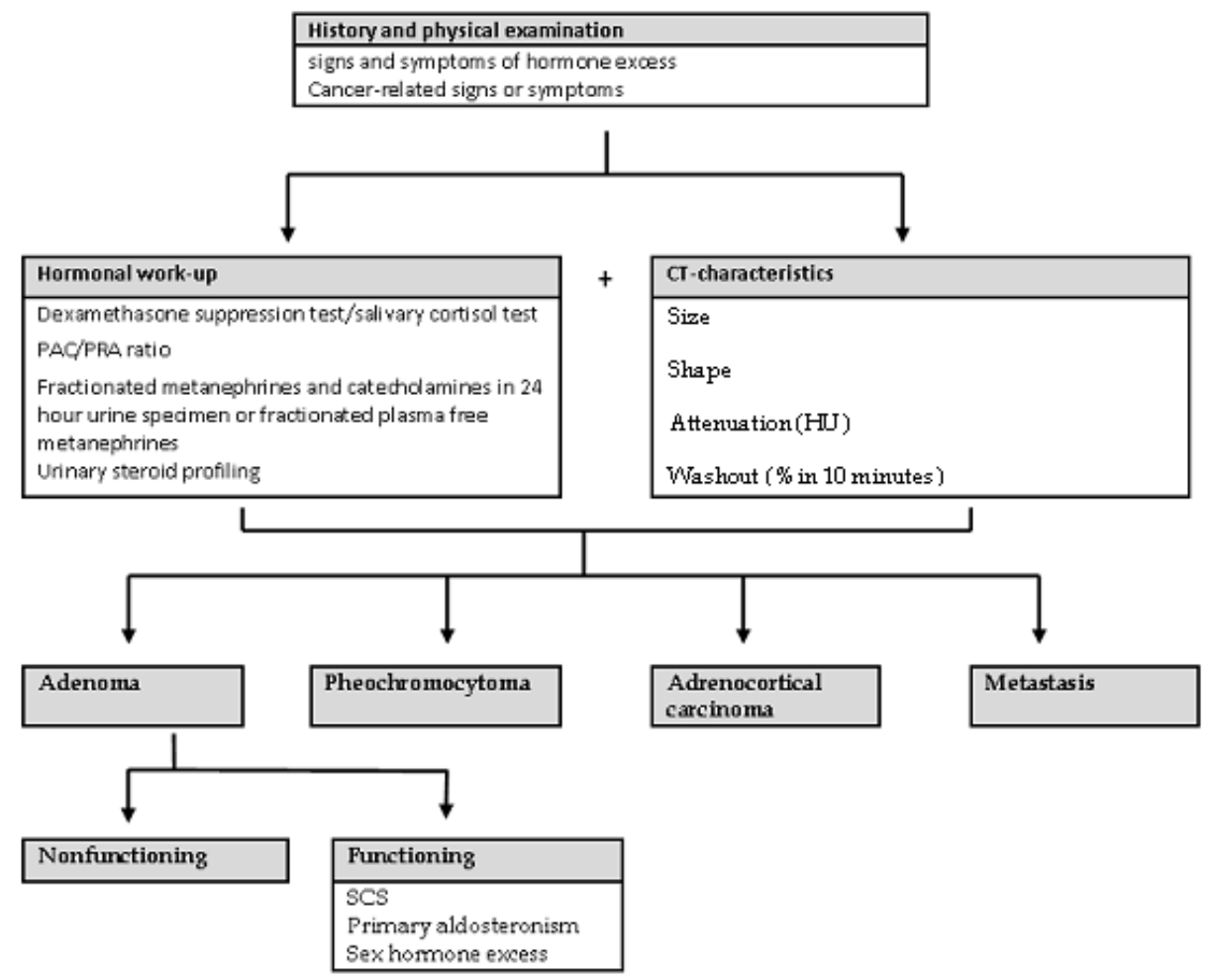

PPAC $/$ PRA ratio = plasma aldosterone concentration to plasma renin activity ratio. HU = Hounsfield Units. SCS = Subclinical Cushing's Syndrome.

Fig. 3. Algorithm for diagnostic evaluation of adrenal incidentaloma 


\section{Surgical treatment of incidentaloma}

Based on results of the diagnostic evaluation of the adrenal incidentaloma, decisions are made regarding the required therapeutic approach. However, a prospective randomized comparison of laparoscopic versus open adrenalectomy has not yet been performed. Recommendations are made based on little known evidence and pragmatism.

\subsection{Adenoma}

When an adrenocortical adenoma is suspected, subsequent management is founded on size of the mass and functionality. As mentioned, in case of overproduction of cortisol, aldosterone or sex hormones, surgical resection of the mass is the treatment of choice. Mortality associated with adrenalectomy is estimated at less than 2\% (Grumbach et al. 2003). Laparoscopic approach allows for a minimal invasive procedure associated with less morbidity in the patient and shorter period of hospitalization, while surgical results are comparable if performed by an experienced surgical team (Gill 2001). An important issue in resection of functioning adrenal masses is steroid suppletion peri- and postoperatively, because of the risk of adrenal insufficiency, hemodynamic crisis and death. In most cases this can be tapered over time.

It is common practice to perform a surgical resection of incidentalomas larger then $6 \mathrm{~cm}$, even if they are non-functioning and there are no signs of malignancy. It is unclear whether this is a good indication for a surgical resection, as follow-up might be sufficient as well. In lesions smaller than $4 \mathrm{~cm}$, surgical resection is deemed not necessary and follow-up is generally accepted as the correct management. For lesions between $4 \mathrm{~cm}$ and $6 \mathrm{~cm}$ in diameter, a clear recommendation is lacking. In this group, surgery might be the safest option regarding the increasing risk of malignancy, however the number needed to treat with respect to curing a carcinoma will be large. The other option is to repeat medical imaging on a shorter term, for example 3 months. We expect urinary steroid profiling to become a valuable instrument in differentiating between benign and malignant lesions in this particular subgroup.

\subsection{Pheochromocytoma}

In patients with an adrenal incidentaloma and suspicion of a pheochromocytoma, rapid surgical resection is the standard curative option, associated with an excellent prognosis (Terzolo et al. 2009). Due to potential perioperative catecholamine excess, removal of a pheochromocytoma is accompanied with unusual hemodynamic and technical conditions, which require thorough preoperative medical preparation and adrenergic blockade to minimize perioperative cardiovascular morbidity. Furthermore, close perioperative monitoring is mandatory (Gill 2001; Ichikawa et al. 2002). Catecholamine release is suggested to be lower during laparoscopy than open adrenalectomy. Therefore, and because of the other benefits of laparoscopic surgery mentioned earlier, a laparoscopic approach is recommended in patients with an incidentaloma suspected for a pheochromocytoma (Cheah et al. 2002; Matsuda et al. 2002).

\subsection{Adrenocortical carcinoma}

A radical surgical resection is the only chance of cure for patients with an adrenocortical carcinoma, so an aggressive surgical approach is warranted (Dackiw et al. 2001; Miller et al. 2010). A complete resection is possible in most cases when the diagnosis is suspected pre- 
operatively. Success rates drop significantly in cases where a carcinoma is not recognized before or during surgery, as follows from own observations from the authors. This emphasizes the need of a complete diagnostic work-up before the patient is directed for a surgical resection of an incidentaloma. The surgeon has to be prepared to perform an extensive resection and to keep the tumour capsule intact, as tumour spill is strongly associated with the occurrence of peritoneal carcinomatosis and a poor prognosis (Dackiw et al. 2001; Schteingart et al. 2005). Therefore, several authors recommend an open surgical approach instead of a laparoscopic technique, which is being used increasingly in adrenal surgery (Gonzalez et al. 2005; Zografos et al. 2009; Leboulleux et al. 2010; Miller et al. 2010). This topic is controversial, as prospective studies are lacking and retrospective studies show contradictory results. It is our belief that in general, a laparotomy is the safest option with respect to achieving a complete resection, although an expert surgeon in laparoscopic adrenalectomies might achieve better results than a less experienced surgeon can achieve performing a laparotomy.

We therefore recommend that these patients should be treated by a multidisciplinary team with at least an endocrinologist, a surgeon, an oncologist, a pathologist and an experienced radiologist. The team should evaluate all patients with a suspect adrenal incidentaloma and decide on which patients will be treated surgically. Peri-operative hydrocortisone suppletion is recommended in all patients. The surgical technique should be determined with respect to the preference and specific qualities of the surgeon. The pathological examination of the tumour requires special attention, as carcinomas might be difficult to recognize. Rating systems as the Weiss-score and the Van Slooten score should be applied to all adrenal tumours. Close follow-up using medical imaging is strongly recommended as the risk of recurrence is high, even after complete resection. The debate regarding adjuvant therapy with mitotane is still ongoing, but it is the opinion of the authors that this is recommended if the tumor has a ki-67 index $>10 \%$ (Terzolo et al. 2007).

\section{Follow-up of nonfunctioning adenoma}

A much discussed matter in the management of patients with an non-functioning adrenal adenoma is the frequency and duration of follow-up evaluation. Recommendations regarding follow-up are aimed at identifying changes in size or functionality of the adrenal adenoma and to recognize lesions with malignant potential that have escaped detection on primary analysis. Research suggests that approximately $8 \%$ of non-functional adrenal incidentalomas increase in size by at least $1 \mathrm{~cm}$ during follow-up, whereas 3-4\% decrease in size (Singh and Buch 2008, Young, Jr. 2000). The majority of adrenal adenomas remain stable. In contrast, adrenocortical carcinomas usually display rapid growth. It is recommended to repeat adrenal imaging by CTscan in patients with nonfunctioning adenomas smaller than $4 \mathrm{~cm}$ within 6-12 months after the initial discovery to detect size changes (Grumbach et al. 2003).

Approximately $20 \%$ of adrenal adenomas which displayed no excess hormone secretion at time of discovery, become autonomous during subsequent period of 4 years. Lesions of at least $3 \mathrm{~cm}$ in diameter are more likely to develop subclinical hyperfunction in contrast to smaller tumors (Androulakis et al. 2011). It is reported that the risk seems to disappear after 3-4 years follow-up. Hyperaldosteronism or catecholamine hypersecretion occurs rarely during follow-up (Grumbach et al. 2003). Cortisol overproduction is more likely to occur. Hence, annual repetition of hormonal work-up, including late-night salivary cortisol and/or overnight dexamethasone $(1 \mathrm{mg})$ suppression test is recommended during 4 years of follow- 
up. Whether measurement of PAC/PRA ratio and determination of fractionated metanephrines and catecholamines in 24-hour urine specimen or fractionated plasma free metanephrines should be repeated, is left to the discretion of the clinician as the indication may vary per patient.

Further follow-up is not indicated in patients with an adrenal mass that remains stable on two imaging studies, done at least 6 months apart and do not demonstrate hormonal overproduction during 4 years of follow-up (Grumbach et al. 2003). Recommendations regarding follow-up of patients with a functional adenoma who are surgically treated, have not been developed.

\begin{tabular}{|c|c|c|}
\hline Suspicion & Management & Considerations \\
\hline \multicolumn{3}{|l|}{ Adenoma } \\
\hline Functioning & Laparoscopic resection & $\begin{array}{l}\text { Post-operative steroid } \\
\text { hormone suppletion }\end{array}$ \\
\hline \multicolumn{3}{|l|}{ Nonfunctioning } \\
\hline$<4 \mathrm{~cm}$ & $\begin{array}{l}\text { Follow-up } \\
-\quad \text { CT-scan within 6-12 months } \\
-\quad \text { Hormonal work-up annually } \\
\text { during } 4 \text { years }\end{array}$ & \\
\hline $4-6 \mathrm{~cm}$ & $\begin{array}{ll}\text { Risk group: } \\
\text { - } \quad \text { Repeat CT-scan within } 6 \text { months } \\
\text { - } \quad \text { Consider surgical resection } \\
\text { - } \quad \text { Urinary steroid profiling } \\
-\quad \text { Consider referral to specialized } \\
\quad \text { centre }\end{array}$ & $\begin{array}{l}\text { Suspicious imaging } \\
\text { phenotype: open } \\
\text { adrenalectomy }\end{array}$ \\
\hline$>6 \mathrm{~cm}$ & Laparoscopic resection & \\
\hline Pheochromocytoma & Laparoscopic resection & Pre-operative preparation \\
\hline $\begin{array}{l}\text { Adrenocortical } \\
\text { carcinoma }\end{array}$ & $\begin{array}{l}\text { Referral to specialized centre } \\
\text { Open adrenalectomy by specialized } \\
\text { surgical team }\end{array}$ & $\begin{array}{l}\text { Post-operative steroid } \\
\text { hormone suppletion } \\
\text { Additional treatment } \\
\text { depending on stage }\end{array}$ \\
\hline
\end{tabular}

Fig. 4. Recommendations for management of adrenal incidentaloma

\section{Treatment in advanced stages}

\subsection{Introduction}

The occurrence of metastatic disease in patients with adrenocortical carcinoma is not rare, as $35 \%$ of patients present with stage 4 disease. $50 \%$ of patients who initially have had a curative resection, ultimately suffer a recurrence (Pommier \& Brennan 1992; Stojadinovic et al. 2002). Even in advanced stages, a surgical debulking should be considered as our own observations indicate this might give a survival benefit. The backbone of treatment in advanced stages is formed by drug therapy with mitotane. Cytotoxic chemotherapy may be added, but response percentages vary. The role of radiation therapy remains disputed. Current experimental treatments include IGF-R blockers (OSI-906) and sunitinib. 


\subsection{Surgery}

In their recent review article, Fassnacht and Allolio provide a flowchart for management of ACC, which advocates at least consideration of surgery in every stage of disease (Fassnacht \& Allolio 2009). Surgery including metastasectomy should at least be considered in stage IV patients and should be pursued if technically feasible and if the patient is motivated and in appropriate physical condition. On the other hand, the absolute survival gain might not weigh up against morbidity after surgery in certain (older) patients. This implies that the decision to perform surgery should be tailored to individual cases and should be discussed in a multidisciplinary team including an experienced surgeon. An additional benefit in cases of hormonal overproduction is that surgery might help controlling hormonal excess (Fassnacht \& Allolio 2009).

Repeat surgery should be considered individually, results indicate that this could be beneficial with regard to survival, especially if the interval between the two operations is more than 6 months (Allolio \& Fassnacht 2006; Veytsman et al. 2009).

\subsection{Mitotane}

Mitotane is the only adrenal-specific agent available for the treatment of ACC (Haak et al. 1994). The exact mechanism of action is not known, but it is proposed and generally accepted that mitotane is metabolized in adrenal mitochondria and causes cytotoxicity by oxidative damage through the production of free radicals (Veytsman et al. 2009). Whatever the exact pathway may be, the main effect is focal degeneration of the fascicular and (particularly) the reticular zone, which clinically leads to adrenal insufficiency for which glucocorticoid substitution is needed. (Hahner \& Fassnacht 2005).

When describing results of mitotane, one should differentiate between antitumor- and antihormonal effects. Regarding antitumor activity, mitotane has been assessed in several clinical studies, with variable results. Most studies were retrospective and comprised only small numbers of patients. Results show that mitotane does have activity against ACC. Percentages vary, but most investigators report total or partial tumor responses in about $25 \%$ to $30 \%$ of cases.

Concerning hormone excess, therapy with mitotane is sufficient in the majority of patients. However, the onset of mitotane is slow due to its lipophilic properties and the resulting accumulation in adipose tissues. It can take up to three months before therapeutic levels are established, so in patients with severe hypercortisolism another agent must be used concurrently to treat this condition while mitotane levels are being built up. The recommended treatment in this situation would be ketoconazol, which is generally well tolerated. Other options, dependent on the case at hand, could be etomidate, mifeprestone or metyrapone (Igaz et al. 2008; Veytsman et al. 2009).

Mitotane treatment with a plasma concentration $>14 \mathrm{mg} / \mathrm{L}$ is associated with prolonged survival (Haak et al. 1994). Adverse effects occur in over $80 \%$ of patients and involve mainly the gastro-intestinal tract: anorexia, nausea, vomiting and diarrhea are frequently observed (Hahner \& Fassnacht 2005). Reported symptoms caused by effects on the central nervous system are ataxia, speed disturbances, confusion and somnolence. Typically, all adverse effects are reversible after mitotane withdrawal (Lanser et al. 1992).

It is important to bear in mind that mitotane not only has adrenolytic effects, impairing adrenal steroidogenesis and thus inducing a need for replacement hydrocortisone, but also stimulates peripheral cortisol metabolism, so that hydrocortisone should be administered in higher doses. A second issue in managing patients on mitotane is monitoring thyroid 
hormone and thyroid stimulating hormone levels, as mitotane can decrease thyroid hormone as well. A third and possibly favorable interaction is the supposedly increased efficacy of cytotoxic chemotherapy when combined with mitotane. However, evidence on this topic is not conclusive. The proposed mechanism for this synergistic effect is the possible negative effect of mitotane on multidrug resistance proteins, as investigated in vitro, which could decrease the resistance of adrenocortical cancer cells to cytotoxic agents (Hahner \& Fassnacht 2005; Igaz et al. 2008).

Given the rarity of the indication and use of mitotane, it is recommended to leave treatment with mitotane to experienced doctors who are familiar with possible adverse events and are able to manage them.

\subsection{Cytotoxic chemotherapy}

Regarding cytotoxic chemotherapy, several combinations of agents have been tried so far. The highest response rates have been found in a trial with a treatment regimen combining mitotane with etoposide, doxorubicine and cisplatin (response rate $49 \%$ ) and another trial with a treatment regimen combining mitotane and streptozotocine (response rate 36\%) (Berruti et al. 2005), (Khan et al. 2000). Recently, these two regimens were compared in the First International Trial in Locally Advanced and Metastatic Adrenocortical Cancer (FIRMACT). Results of this trial are expected in 2011.

\subsection{Radiation therapy}

Whether there is a place for radiation therapy in the treatment of adrenocortical carcinoma, is not yet clear according to the literature. Some authors claim to have accomplished favorable results, like prevention of local recurrence and adequate pain relief in metastatic disease, whereas toxicity was low (Fassnacht et al. 2006; Polat et al. 2009; Hermsen et al. 2010).

Other investigators recommend a more conservative approach, seeing that re-operations in a post-radiation tumor bed would be more difficult and that the favorable results are not all too convincing, given the retrospective character of research so far (Veytsman et al. 2009). One could argue that radiation therapy can be of use in a palliative setting, especially in alleviating pain or neurologic complaints caused by metastatic disease in bone or brain and that a prospective trial is needed to determine the efficacy in an adjuvant setting.

\subsection{Future therapeutic agents}

The insulin-like growth factor receptor (IGF-R) in adrenocortical carcinoma is regarded as a possible target for treatment. Both antibody and tyrosine kinase inhibitor trials targeted against IGF-R are in progress. A trial using sunitinib as therapeutic agent produced disappointing results, but a better understanding of the metabolic complexity of the disease might lead to better trials in the future. Other areas of interest are VEGFR inhibitors and FGFR inhibitors, but these have not been translated into clinical trials yet.

\section{Limitations}

Due to limited evidence and guidelines, there are still multiple unresolved issues regarding management of incidentalomas, mainly concerning the duration of follow-up. The most important health risk in patients with an incidentaloma is related to several 
characteristics of the adrenal mass associated with a malignant mass or pheochromocytoma (Kievit \& Haak 2000). The rate of growth of a benign adrenal lesion remains unclear. Besides this, the percentage of patients that will develop hormonal overproduction when initial analysis was negative is uncertain as well. Furthermore, there is some concern regarding the side effects of repeated CT imaging. One report estimated the risk of fatal cancer due to exposure to ionising radiation during CT-imaging to be one in 430-2170 (Androulakis et al. 2011). This is comparable to the chance of developing an adrenocortical carcinoma during 3-year follow-up of an incidentaloma. Additionally, a long follow-up period with repeated extensive hormonal work-up and radiological imaging is associated with high costs. Since the frequency of discovered adrenal incidentalomas is expected to increase and the use of abdominal imaging is also increasing, the cost-effectiveness of repeated hormonal work-up and imaging becomes an important issue in health care. However, in practice, choices of follow-up or treatment are also based on psychological or social mechanisms, such as anxiety, doubt and risk aversion as well as cost-effectiveness. To elucidate these uncertainties prospective trials are warranted to evaluate the optimal diagnostic approach and management of an incidentaloma and provide an answer for unresolved questions.

\section{Organization of care}

The rarity of a number of adrenal disorders, such as ACC or pheochromocytoma, and the dismal prognosis associated with an adrenal malignancy, requires a multidisciplinary approach of each patient. In the event of an ACC, physicians often are not familiar with the disorder and its few available treatment options, resulting in inferior patient care. Given that a large part of diagnostics and management is based on pragmatism and expert opinion instead of prospective trials, additional studies concerning treatment and follow-up of adrenal tumors are necessary. In order to improve care in patients with adrenal disorders and stimulate scientific research, national and international collaboration is vital. In a number of European countries (France, Germany, Italy, The Netherlands), national networks have been set up to coordinate adrenal diseases-research and - patient care. (Koschker et al. 2006; van Ditzhuijsen et al. 2007)

In the southern region of The Netherlands, our hospital acts as a tertiary referral center for patients with adrenal tumors. We have provided local hospitals with a guideline for diagnostics and patient referral similar to the procedure described in this chapter. The subsequent centralization of these patients facilitates reliable pre-operative diagnostics and specialized surgery, of which the importance cannot be overemphasized. Too many patients each year see their chance of survival be ruined because an adrenal malignancy is not recognized before, during or even after surgery. Irradical resection and/or rupture of the tumor capsule in adrenocortical carcinoma is fatal without exception, but can often be prevented if treated by experienced doctors.

Therefore, we strongly support initiatives of centralization being deployed in other regions and countries, as the beneficial effects of specialization have been proven multiple times in other rare diseases (Sosa et al. 1998; Kumar et al. 2001). Centralization and multidisciplinary approach is associated with more complete resections, improved survival and enhanced patient care. A secondary benefit is the facilitation of scientific research and participation in clinical trials in centralized populations of patients with a rare disease. 


\section{Conclusion}

Due to the increasing discovery of adrenal incidentalomas, the diagnostic work-up as well as the management of incidentalomas is a growing public health challenge. Hormonal functionality and malignant potential of the lesion need to be evaluated. Incidentalomas are mostly benign nonhypersecretory adrenal adenomas, however important diagnoses to exclude are (subclinical) Cushing's Syndrome, primary aldosteronism, sex hormone overproduction, pheochromocytoma or malignancy (e.g. adrenocortical carcinoma, metastasis). Surgical treatment is recommended in all patients with a hormonally active tumor or a tumor larger than $6 \mathrm{~cm}$. Furthermore, surgery may be indicated in individual cases depending on radiological characteristics. In patients with nonfunctioning adrenal adenomas smaller than $4 \mathrm{~cm}$ follow-up with CT-scan after 6-12 months and annual hormonal work-up for 4 years is recommended. An adrenocortical carcinoma is rare, but often lethal. Surgery is the cornerstone of initial treatment, whereas drug therapy with mitotane is inevitable in advanced stages. It is recommended that patients with adrenal disorders are treated in a multidisciplinary setting by experienced physicians. Centralization of care is strongly encouraged in order to improve patient outcome and to stimulate research and trial participation.

\section{References}

Allolio,B. \& Fassnacht,M. 2006. Clinical review: Adrenocortical carcinoma: clinical update. J Clin Endocrinol. Metab, 91, 2027-2037.

Androulakis,I.I., Kaltsas,G., Piaditis,G. \& Grossman,A.B. 2011. The clinical significance of adrenal incidentalomas. Eur J Clin Invest, 41, 552-560.

Berruti,A., Terzolo,M., Sperone,P., Pia,A., Casa,S.D., Gross,D.J., Carnaghi,C., Casali,P., Porpiglia,F., Mantero,F., Reimondo,G., Angeli,A. \& Dogliotti,L. 2005. Etoposide, doxorubicin and cisplatin plus mitotane in the treatment of advanced adrenocortical carcinoma: a large prospective phase II trial. Endocr. Relat Cancer, 12, 657-666.

Boland,G.W. 2011. Adrenal imaging: why, when, what, and how? Part 3. The algorithmic approach to definitive characterization of the adrenal incidentaloma. AJR Am J Roentgenol., 196, W109-W111.

Cheah,W.K., Clark,O.H., Horn,J.K., Siperstein,A.E. \& Duh,Q.Y. 2002. Laparoscopic adrenalectomy for pheochromocytoma. World J Surg, 26, 1048-1051.

Dackiw,A.P., Lee,J.E., Gagel,R.F. \& Evans,D.B. 2001. Adrenal cortical carcinoma. World J Surg, 25, 914-926.

Fassnacht,M. \& Allolio,B. 2009. Clinical management of adrenocortical carcinoma. Best. Pract. Res. Clin Endocrinol. Metab, 23, 273-289.

Fassnacht,M., Hahner,S., Polat,B., Koschker,A.C., Kenn,W., Flentje,M. \& Allolio,B. 2006. Efficacy of adjuvant radiotherapy of the tumor bed on local recurrence of adrenocortical carcinoma. J Clin Endocrinol. Metab, 91, 4501-4504.

Gill,I.S. 2001. The case for laparoscopic adrenalectomy. J Urol., 166, 429-436.

Gonzalez,R.J., Shapiro,S., Sarlis,N., Vassilopoulou-Sellin,R., Perrier,N.D., Evans,D.B. \& Lee,J.E. 2005. Laparoscopic resection of adrenal cortical carcinoma: a cautionary note. Surgery, 138, 1078-1085. 
Grumbach,M.M., Biller,B.M., Braunstein,G.D., Campbell,K.K., Carney,J.A., Godley,P.A., Harris,E.L., Lee,J.K., Oertel,Y.C., Posner,M.C., Schlechte,J.A. \& Wieand,H.S. 2003. Management of the clinically inapparent adrenal mass ("incidentaloma"). Ann Intern Med, 138, 424-429.

Haak,H.R., Hermans,J., van de Velde,C.J., Lentjes,E.G., Goslings,B.M., Fleuren,G.J. \& Krans,H.M. 1994. Optimal treatment of adrenocortical carcinoma with mitotane: results in a consecutive series of 96 patients. Br J Cancer, 69, 947-951.

Hahner,S. \& Fassnacht,M. 2005. Mitotane for adrenocortical carcinoma treatment. Curr. Opin. Investig. Drugs, 6, 386-394.

Hamrahian,A.H., Ioachimescu,A.G., Remer,E.M., Motta-Ramirez,G., Bogabathina,H., Levin,H.S., Reddy,S., Gill,I.S., Siperstein,A. \& Bravo,E.L. 2005. Clinical utility of noncontrast computed tomography attenuation value (hounsfield units) to differentiate adrenal adenomas/hyperplasias from nonadenomas: Cleveland Clinic experience. J Clin Endocrinol. Metab, 90, 871-877.

Hermsen,I.G., Groenen,Y.E., Dercksen,M.W., Theuws,J. \& Haak,H.R. 2010. Response to Radiation Therapy in Adrenocortical Carcinoma. J Endocrinol. Invest.

Ichikawa,T., Mikami,K., Suzuki,H., Imamoto,T., Yamazaki,T., Naya,Y., Ueda,T., Igarashi,T. \& Ito,H. 2002. Laparoscopic adrenalectomy for pheochromocytoma. Biomed. Pharmacother., 56 Suppl 1, 149s-153s.

Igaz,P., Tombol,Z., Szabo,P.M., Liko,I. \& Racz,K. 2008. Steroid biosynthesis inhibitors in the therapy of hypercortisolism: theory and practice. Curr Med Chem., 15, 2734-2747.

Khan,T.S., Imam,H., Juhlin,C., Skogseid,B., Grondal,S., Tibblin,S., Wilander,E., Oberg,K. \& Eriksson,B. 2000. Streptozocin and o,p'DDD in the treatment of adrenocortical cancer patients: long-term survival in its adjuvant use. Ann Oncol, 11, 1281-1287.

Kievit,J. \& Haak,H.R. 2000. Diagnosis and treatment of adrenal incidentaloma. A costeffectiveness analysis. Endocrinol. Metab Clin North Am, 29, 69-ix.

Koschker,A.C., Fassnacht,M., Hahner,S., Weismann,D. \& Allolio,B. 2006. Adrenocortical carcinoma -- improving patient care by establishing new structures. Exp. Clin Endocrinol. Diabetes, 114, 45-51.

Kumar,H., Daykin,J., Holder,R., Watkinson,J.C., Sheppard,M.C. \& Franklyn,J.A. 2001. An audit of management of differentiated thyroid cancer in specialist and nonspecialist clinic settings. Clin Endocrinol. (Oxf), 54, 719-723.

Lanser,J.B., van Seters,A.P., Moolenaar,A.J., Haak,H.R. \& Bollen,E.L. 1992. Neuropsychologic and neurologic side effects of mitotane and reversibility of symptoms. J Clin Oncol, 10, 1504.

Leboulleux,S., Deandreis,D., Al,G.A., Auperin,A., Goere,D., Dromain,C., Elias,D., Caillou,B., Travagli,J.P., De,B.T., Lumbroso,J., Young,J., Schlumberger,M. \& Baudin,E. 2010. Adrenocortical carcinoma: is the surgical approach a risk factor of peritoneal carcinomatosis? Eur J Endocrinol..

Matsuda,T., Murota,T., Oguchi,N., Kawa,G. \& Muguruma,K. 2002. Laparoscopic adrenalectomy for pheochromocytoma: a literature review. Biomed. Pharmacother., 56 Suppl 1, 132s-138s. 
Miller,B.S., Ammori,J.B., Gauger,P.G., Broome,J.T., Hammer,G.D. \& Doherty,G.M. 2010. Laparoscopic Resection is Inappropriate in Patients with Known or Suspected Adrenocortical Carcinoma. World J Surg.

Nieman,L.K. 2010. Approach to the patient with an adrenal incidentaloma. J Clin Endocrinol. Metab, 95, 4106-4113.

Polat,B., Fassnacht,M., Pfreundner,L., Guckenberger,M., Bratengeier,K., Johanssen,S., Kenn,W., Hahner,S., Allolio,B. \& Flentje,M. 2009. Radiotherapy in adrenocortical carcinoma. Cancer, 115, 2816-2823.

Pommier,R.F. \& Brennan,M.F. 1992. An eleven-year experience with adrenocortical carcinoma. Surgery, 112, 963-970.

Quayle,F.J., Spitler,J.A., Pierce,R.A., Lairmore,T.C., Moley,J.F. \& Brunt,L.M. 2007. Needle biopsy of incidentally discovered adrenal masses is rarely informative and potentially hazardous. Surgery, 142, 497-502.

Schteingart,D.E., Doherty,G.M., Gauger,P.G., Giordano,T.J., Hammer,G.D., Korobkin,M. \& Worden,F.P. 2005. Management of patients with adrenal cancer: recommendations of an international consensus conference. Endocr. Relat Cancer, 12, 667-680.

Singh,P.K. \& Buch,H.N. 2008. Adrenal incidentaloma: evaluation and management. J Clin Pathol, 61, 1168-1173.

Sosa,J.A., Bowman,H.M., Tielsch,J.M., Powe,N.R., Gordon,T.A. \& Udelsman,R. 1998. The importance of surgeon experience for clinical and economic outcomes from thyroidectomy. Ann Surg, 228, 320-330.

Stojadinovic,A., Ghossein,R.A., Hoos,A., Nissan,A., Marshall,D., Dudas,M., CordonCardo,C., Jaques,D.P. \& Brennan,M.F. 2002. Adrenocortical carcinoma: clinical, morphologic, and molecular characterization. J Clin Oncol, 20, 941-950.

Taylor A \& Arlt,W. Urinary Steroid Profiling as a High-Throughput Screening Tool for the Detection of Malignancy in Patients with Adrenal Tumors. Society for Endocrinology BES 2010 Abstract, 3-72. 2010.

Terzolo,M., Angeli,A., Fassnacht,M., Daffara,F., Tauchmanova,L., Conton,P.A., Rossetto,R., Buci,L., Sperone,P., Grossrubatscher,E., Reimondo,G., Bollito,E., Papotti,M., Saeger,W., Hahner,S., Koschker,A.C., Arvat,E., Ambrosi,B., Loli,P., Lombardi,G., Mannelli,M., Bruzzi,P., Mantero,F., Allolio,B., Dogliotti,L. \& Berruti,A. 2007. Adjuvant mitotane treatment for adrenocortical carcinoma. N Engl J Med, 356, 2372-2380.

Terzolo,M., Bovio,S., Pia,A., Reimondo,G. \& Angeli,A. 2009. Management of adrenal incidentaloma. Best. Pract. Res Clin Endocrinol. Metab, 23, 233-243.

van Ditzhuijsen,C.I., van de,W.R. \& Haak,H.R. 2007. Adrenocortical carcinoma. Neth. J Med, $65,55-60$.

Veytsman,I., Nieman,L. \& Fojo,T. 2009. Management of Endocrine Manifestations and the Use of Mitotane as a Chemotherapeutic Agent for Adrenocortical Carcinoma. J Clin Oncol.

Young,W.F., Jr. 2000. Management approaches to adrenal incidentalomas. A view from Rochester, Minnesota. Endocrinol. Metab Clin North Am., 29, 159-85, x. 
Young,W.F., Jr. 2007. Clinical practice. The incidentally discovered adrenal mass. N. Engl. J Med, 356, 601-610.

Zografos,G.N., Vasiliadis,G., Farfaras,A.N., Aggeli,C. \& Digalakis,M. 2009. Laparoscopic surgery for malignant adrenal tumors. JSLS., 13, 196-202. 


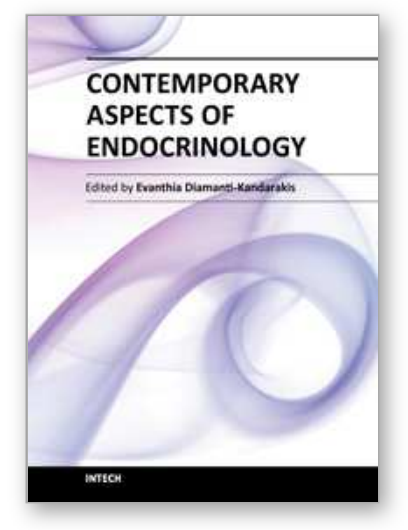

\author{
Contemporary Aspects of Endocrinology \\ Edited by Dr. Evanthia Diamanti-Kandarakis
}

ISBN 978-953-307-357-6

Hard cover, 454 pages

Publisher InTech

Published online 30, November, 2011

Published in print edition November, 2011

This book aims to provide readers with a general as well as an advanced overview of the key trends in endocrine disorders. While covering a variety of topics ranging from thyroid carcinogenesis and pituitary adenomas to adrenal tumors and metabolic bone disease, this book also focuses on more specific issues not yet fully elucidated (e.g. the molecular pathways involved in thyrotropin beta gene regulation or monogenic phosphate balance disorders). Readers of different fields and background will have the opportunity to update their knowledge and more importantly to clarify areas of uncertainty and controversies in several topics of endocrine disorders.

\title{
How to reference
}

In order to correctly reference this scholarly work, feel free to copy and paste the following:

S.H.A. Brouns, T.M.A. Kerkhofs, I.G.C. Hermsen and H.R. Haak (2011). Adrenal Incidentaloma and Adrenocortical Carcinoma: A Clinical Guideline on Treating the Unexpected and a Plea for Specialized Care, Contemporary Aspects of Endocrinology, Dr. Evanthia Diamanti-Kandarakis (Ed.), ISBN: 978-953-307-357-6, InTech, Available from: http://www.intechopen.com/books/contemporary-aspects-of-endocrinology/adrenalincidentaloma-and-adrenocortical-carcinoma-a-clinical-guideline-on-treating-the-unexpected-a

\section{INTECH}

open science | open minds

\section{InTech Europe}

University Campus STeP Ri

Slavka Krautzeka 83/A

51000 Rijeka, Croatia

Phone: +385 (51) 770447

Fax: +385 (51) 686166

www.intechopen.com

\section{InTech China}

Unit 405, Office Block, Hotel Equatorial Shanghai

No.65, Yan An Road (West), Shanghai, 200040, China

中国上海市延安西路65号上海国际贵都大饭店办公楼405单元

Phone: $+86-21-62489820$

Fax: +86-21-62489821 
(C) 2011 The Author(s). Licensee IntechOpen. This is an open access article distributed under the terms of the Creative Commons Attribution 3.0 License, which permits unrestricted use, distribution, and reproduction in any medium, provided the original work is properly cited. 